\title{
Crocodile blood extract induces the apoptosis of lung cancer cells through PTEN activity
}

\author{
YUQIAN OU $^{1}$ and WING SHING $\mathrm{HO}^{1,2}$ \\ ${ }^{1}$ School of Life Sciences, The Chinese University of Hong Kong; ${ }^{2}$ HTL R\&D, Ltd., \\ Hong Kong Science \& Technology Parks Corporation, Shatin, NT, Hong Kong, SAR, P.R. China
}

Received April 7, 2016; Accepted May 17, 2016

DOI: $10.3892 /$ or.2016.4914

\begin{abstract}
Current treatment strategies for lung cancer cause undesirable side-effects. Integrated medicine with a curative approach has become a common approach to the treatment strategy. Recent studies suggest that American alligator blood is effective in reducing colorectal cancer cell viability in vitro, but the mechanism remains unclear. In the present study, we aimed to study the anticancer activity of crocodile blood extracts on lung cancer cell line A549 and investigate the possible mechanisms involved. In vitro studies were utilized to investigate the effects on the cancer cells after incubation with the blood extracts. The active fraction that showed more efficacy in inhibiting cell growth was characterized in the supernatant (S2) from whole blood extracts. High performance liquid chromatography (HPLC) analysis revealed that S2 contained more polar moiety from whole blood. S2 induced DNA fragmentation. Cell cycle arrest in the G1/M phase was demonstrated and mitochondrial membrane permeability was disrupted. An increase in the generation of reactive oxygen species (ROS) and increased activities of caspase- 3 and caspase- 7 were detected. Furthermore, release of cytochrome $c$, upregulation of expression of Bax, p53, p21, Bid, cleaved forms of the caspase family and PARP along with downregulation of Bcl-2, PCNA, MDM2, caspase-8, wild types of caspase family proteins and PARP were recorded after treatment with S2 fractions. Moreover, the PI3K/AKT survival pathway was downregulated by $\mathrm{S} 2$ fractions in the lung cancer cell line.
\end{abstract}

\section{Introduction}

Lung cancer is one of the leading causes of cancer-related death in the world (1). Treatments of lung cancer vary from stage to stage (2). Common chemotherapy and radiotherapy cause

Correspondence to: Professor Wing Shing Ho, School of Life Sciences, The Chinese University of Hong Kong, MMW 604, Shatin, NT, Hong Kong, SAR, P.R. China

E-mail:ws203ho@cuhk.edu.hk

Key words: lung cancer, cell cycle arrest, apoptosis undesirable side-effects. Conventional therapies at a later stage of cancer development and poor prognosis limit the survival rate of lung cancer patients $(3,4)$. Previous research found that crocodile blood displayed marked effects on cancer cells not only with anti-23 strains of bacteria, including those resistant to antibiotics, but also with antioxidant and anti-inflammatory properties $(5,6)$. Yet the mechanism remains unclear. Our present study aimed to evaluate the effects of crocodile tissue extracts on a lung cancer cell line and studied the related mechanisms of action. An attempt was made to characterize the active fractions.

\section{Materials and methods}

Cell culture. The A549 human lung adenocarcinoma cell line was obtained from the American Type Culture Collection (ATCC; Manassas, VA, USA). Culturing was maintained according to their recommendations. The A549 cell line was cultured in F-12K medium (Invitrogen Life Technologies, Carlsbad, CA, USA) with $10 \%$ fetal bovine serum (FBS) and $1 \%$ penicillin-streptomycin (PS) (both from Gibco, Grand Island, NY, USA) antibiotic solution. All cell cultures and subcultures were incubated at $37^{\circ} \mathrm{C}$ with $5 \% \mathrm{CO}_{2}$.

Whole blood and fraction preparation. Crocodile blood powder was purchased from a local vendor and dissolved in phosphate-buffered saline (PBS). After sonification, the mixture was centrifuged at $10,000 \mathrm{x}$ g for $20 \mathrm{~min}$. The supernatant was collected. After precipitation by ammonium sulfate overnight at $4^{\circ} \mathrm{C}$, the mixture was centrifuged at $10,000 \mathrm{x} \mathrm{g}$ for $20 \mathrm{~min}$. The supernatant and residues were collected and desalted by Sephadex G25.

Fast protein liquid chromatography (FPLC) analysis. An ÄKTA FPLC system (Amersham Pharmacia Biotech, Sweden) and a Sephadex G25 column $(50 \times 4.6 \mathrm{~mm}$; GE Healthcare, USA) were used. The samples were separated at $5 \mathrm{ml} / \mathrm{min}$. The mobile phase was distilled water with a constant elution component. The column temperature was approximately $25^{\circ} \mathrm{C}$ and detected at $280 \mathrm{~nm}$. The detector with conductance was recruited.

High performance liquid chromatography (HPLC) analysis. An Agilent 1100 system (Agilent Technologies, Palo Alto, 
CA, USA) and a Prevail C18 column (250x4.6 mm I.D., $5 \mu \mathrm{m}$; Alltech, USA) were used. The samples were separated by HPLC at a flow rate of $0.8 \mathrm{ml} / \mathrm{min}$. The mobile phase consisted of $0.1 \%$ trifluoroacetic acid in water (A) and acetonitrile (B) with a gradient elution of $5 \% \mathrm{~B}$ at $0-5 \mathrm{~min} ; 20 \% \mathrm{~B}$ at $6-15 \mathrm{~min}$; $30 \% \mathrm{~B}$ at $16-25 \mathrm{~min} ; 60 \% \mathrm{~B}$ at $26-35 \mathrm{~min} ; 90 \% \mathrm{~B}$ at $36-45 \mathrm{~min}$; $5 \% \mathrm{~B}$ at $46-50 \mathrm{~min}$. The column temperature was set at $25^{\circ} \mathrm{C}$ with injection volume of $10 \mu \mathrm{l}$. Detection was set at $280 \mathrm{~nm}$.

Assessment of cell viability by MTT assays. A549 cells were seeded into a 96 -well plate at a density of $1 \times 10^{4}$ cells/well. Cells were treated with different concentrations of sample solution for 24,48 and $72 \mathrm{~h}$, respectively, and those without treatment as control. A total of $50 \mu \mathrm{l}$ of 3-(4,5-dimethylthiazol-2-yl)-2,5-diphenyltetrazolium bromide (MTT; Sigma-Aldrich, St. Louis, MO, USA) solution was added to each well and incubated for $1 \mathrm{~h}$. The purple formazan formed was dissolved in $200 \mu \mathrm{l}$ of DMSO and quantified by measuring the absorbance at $540 \mathrm{~nm}$ with a microplate reader (Tecan Infinite M200; Tecan Group, Switzerland). The relative cell viability was compared to the control. The half maximal inhibitory concentration $\left(\mathrm{IC}_{50}\right)$ was determined according to the relative cell viability curve.

Measurement of cytotoxicity. A549 cells were seeded into a 96-well plate at a density of $1 \times 10^{4}$ cells/well. Cells were treated with different concentrations of sample solution for $24 \mathrm{~h}$. Measurement was carried out according to the manufacturer's instructions (CytoTox 96 Non-Radioactive Cytotoxicity Assay kit, G1780; Promega, Madison, WI, USA). In brief, after centrifugation at $250 \mathrm{x} \mathrm{g}$ for $4 \mathrm{~min}, 50 \mu \mathrm{l}$ of the supernatant was transferred into a new 96-well plate. A total of $50 \mu \mathrm{l}$ of substrate was added and the mixture was incubated for $30 \mathrm{~min}$ at room temperature. Measurement was carried out using a microplate reader at $490 \mathrm{~nm}$.

DNA fragmentation. A549 cells were seeded in 100-mm dishes at a confluency of $5 \times 10^{6}$. The cells were treated with $200 \mu \mathrm{g} / \mathrm{ml}$ of S2 for 24, 48 and $72 \mathrm{~h}$, respectively and harvested with trypsin (Invitrogen Life Technologies) and PBS. The cell pellets were then re-suspended in $500 \mu \mathrm{l}$ of DNA digestion buffer with Proteinase K (BioVision, USA) added to a $0.5 \mathrm{mg} / \mathrm{ml}$ final concentration overnight at $55^{\circ} \mathrm{C}$ with gentle shaking. A total of $700 \mu \mathrm{l}$ of neutralized phenol/chloroform/isoamyl alcohol (25:24:1) was added and mixed fairly vigorously. The samples were spinned at $10,000 \times \mathrm{g}$ for $5 \mathrm{~min}$ and $500 \mu \mathrm{l}$ of the upper phase was transferred to a new microfuge tube. DNA was precipitated with $1 \mathrm{ml} \mathrm{100 \%} \mathrm{ethanol} \mathrm{at} \mathrm{room} \mathrm{temperature} \mathrm{and}$ centrifuged at 10,000 x g. The sample was then washed with $70 \%$ ethanol twice and air dried. The DNA precipitate was dissolved in $50 \mu \mathrm{l}$ of TE buffer and electrophoresed on a $1.5 \%$ agarose gel with GelRed Nucleic Acid Gel Stain (Biotium, Hayward, CA, USA) and detected under UV light.

Cell cycle analysis. After A549 cells grew to 80\% confluency on 100-mm culture dishes, different concentrations of S2 were added after $24 \mathrm{~h}$. The cells were harvested with trypsin and washed with cold PBS twice. After centrifugation at $250 \mathrm{x}$ g for $5 \mathrm{~min}$, the cell pellets were re-suspended in cold $70 \%$ ethanol and fixed at $-20^{\circ} \mathrm{C}$ overnight. The supernatant was discarded after centrifugation at $250 \mathrm{xg}$ for $5 \mathrm{~min}$. The cell pellets were

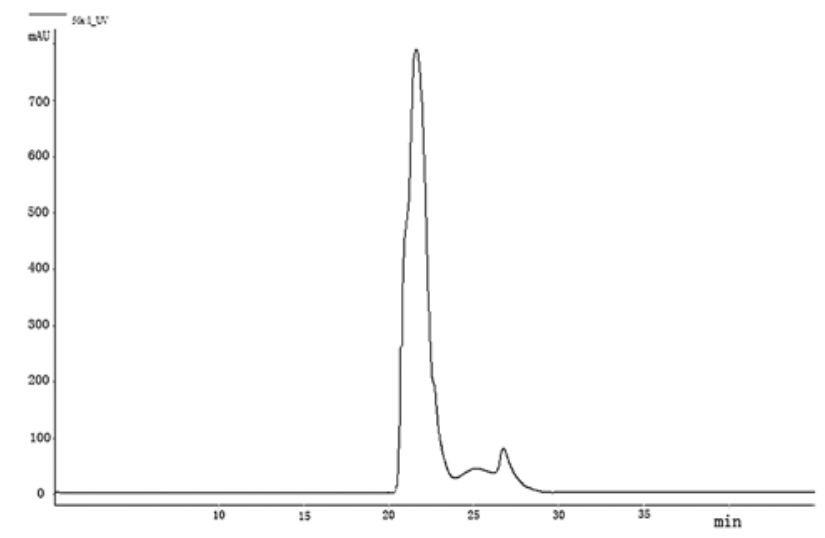

Figure 1. FPLC-UV chromatogram of the supernatant under $280 \mathrm{~nm}$.

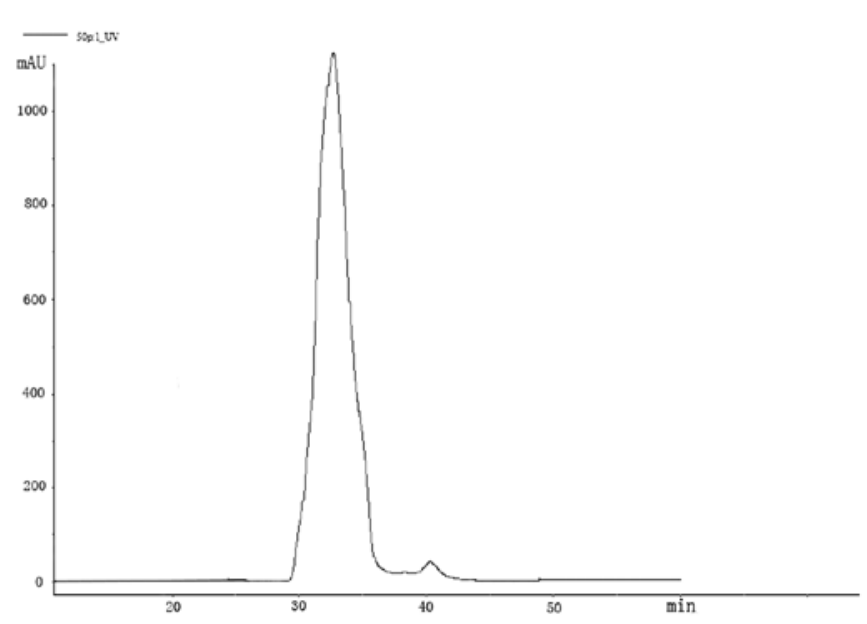

Figure 2. FPLC-UV chromatogram of the residue under $280 \mathrm{~nm}$.

washed with cold PBS twice and re-suspended with $0.5 \mathrm{ml}$ propidium iodide (PI) solution. After incubation at $37^{\circ} \mathrm{C}$ in the dark, the cells were transferred into a $5 \mathrm{ml}$ polystyrene round-bottom tube and sorted with 10,000 events/sample in triplicate using a flow cytometer (BD FACSCanto; BD Biosciences, USA). The results were analyzed with ModFit 3.0 software.

Detection of apoptosis. A549 cells were cultured into 100-mm dishes and treated with different concentrations of S2 for $24 \mathrm{~h}$. After harvesting with trypsin and washing twice with cold PBS, detection was carried out according to the manufacturer's instructions (FITC Annexin V Apoptosis Detection kit; BD Biosciences). In brief, the cell pellets were re-suspended in $0.5 \mathrm{ml}$ of $1 \mathrm{X}$ binding buffer. A total of $5 \mu \mathrm{l}$ Annexin V-FITC solution and $5 \mu 11 \mathrm{X}$ PI solution were added to $100 \mu \mathrm{l}$ of the cell suspension. The mixture was incubated for $15 \mathrm{~min}$ in the dark at room temperature. Before injecting into the flow cytometer, $0.4 \mathrm{ml} 1 \mathrm{X}$ binding buffer was added to each sample mixture. Analysis was achieved with 10,000 events/sample in triplicate using a flow cytometer (BD FACSCanto; BD Biosciences). The results were analyzed with WinMDI 2.9 software.

Mitochondrial membrane permeability. A549 cells were cultured into 6-well plates and treated with different 


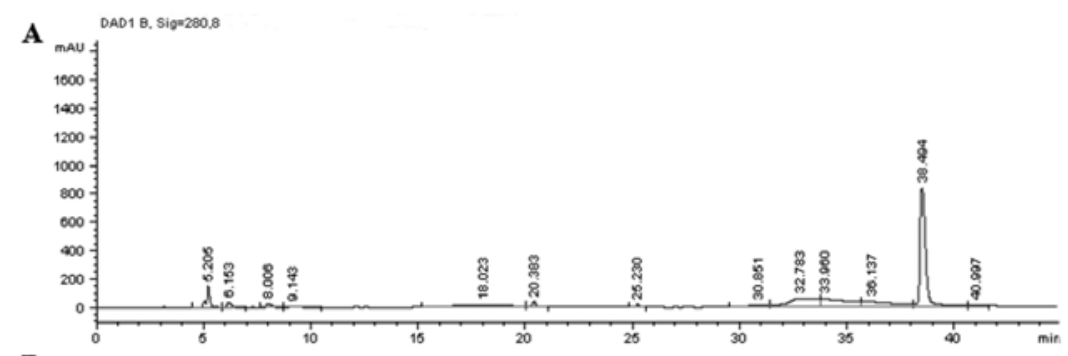

B

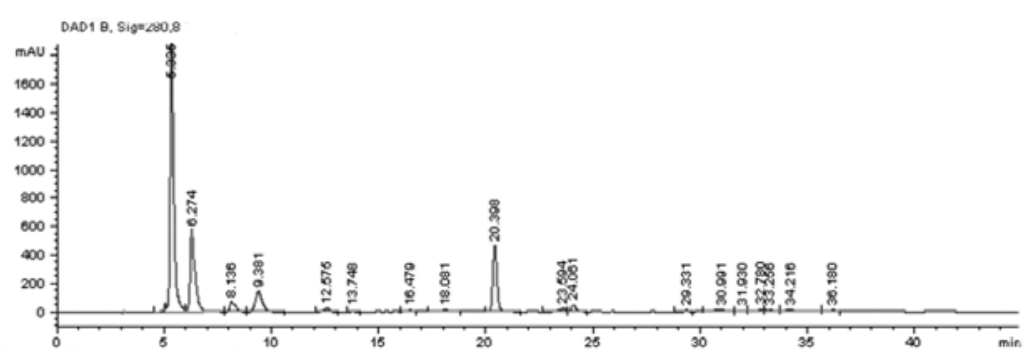

Figure 3. HPLC-DAD chromatogram of whole blood and S2 under $280 \mathrm{~nm}$. (A) Whole blood. (B) S2.

concentrations of S2 for $3 \mathrm{~h}$. After harvesting with trypsin and washing twice with cold PBS, the cell pellets were re-suspended in $0.5 \mathrm{ml}$ of JC-1 solution (MitoScreen kit; BD Biosciences). After incubation for $15 \mathrm{~min}$ at $37^{\circ} \mathrm{C}$ in the dark, the cell mixture was centrifuged at $250 \mathrm{x}$ g for $5 \mathrm{~min}$ and the supernatant was discarded. Before re-suspending with $0.5 \mathrm{ml}$ of $1 \mathrm{X}$ assay buffer solution, the cell pellets were washed twice with $1 \mathrm{ml}$ of $1 \mathrm{X}$ binding buffer at room temperature. Analysis was achieved with 10,000 events/sample in triplicate using a flow cytometer. The results were analyzed with WinMDI 2.9 software.

Measurement of reactive oxygen species (ROS). A549 cells were cultured in 6-well plates with coverslips inside at a density of $1 \times 10^{5}$ cells/well and treated with different concentrations of S2 for $24 \mathrm{~h}$. After washing with warm Hank's Balanced Salt Solution (HBSS; Gibco, Gaithersburg, MD, USA), a sufficient amount of $25 \mu \mathrm{M}$ carboxy- $\mathrm{H}_{2}$ DCFDA (Image-iT ${ }^{\mathrm{TM}}$ LIVE Green Reactive Oxygen Species Detection kit; BD Biosciences) working solution was applied to the coverslips followed by a 30 -min incubation at $37^{\circ} \mathrm{C}$ in the dark. To stain the nucleus, a final concentration of $1.0 \mu \mathrm{M}$ of Hoechst was added to the cells at the last $5 \mathrm{~min}$ of incubation. The coverslips were washed with warm HBSS (Thermo Fisher Scientific, USA) prior to reversely cover the slides with mounting medium. The slides were detected under a fluorescence microscope under a excitation/emission wavelength of 350/461 nm for Hoechst and $495 / 529 \mathrm{~nm}$ for carboxy- $\mathrm{H}_{2}$ DCFDA.

Activities of caspase-3/7. A549 cells were seeded onto 96-well plates at the concentration of $1 \times 10^{4}$ cells/well. The cells were treated with different concentrations of S2 for $24 \mathrm{~h}$. A total of $100 \mu \mathrm{l}$ of $1 \mathrm{X}$ caspase substrate Z-DEVD solution (Apo-ONE Homogeneous Caspase-3/7 Assay kit; Promega) was added to each well (1:1). The mixture was gently mixed using a plate shaker at $250 \mathrm{x} \mathrm{g}$ and incubated at room temperature for $3 \mathrm{~h}$. The fluorescence of each well was measured at 485/520 nm using a microplate reader.
Detection of nuclei, mitochondria and cytochrome c. A549 cells were cultured into 6 -well plates with coverslips inside at a density of $1 \times 10^{5}$ cells/well and treated with different concentrations of S2 for $24 \mathrm{~h}$. An optimal concentration of mitochondrial dye MitoTracker Red (M7512; Invitrogen Life Technologies) was added and incubated for $30 \mathrm{~min}$ at $37^{\circ} \mathrm{C}$. After washing with warm HBSS, $1 \mathrm{ml}$ of $4 \%$ paraformaldehyde was added for $30 \mathrm{~min}$, followed by $0.5 \%$ of Triton-X for $15 \mathrm{~min}$. After washing with PBS, 3\% bovine serum albumin (BSA) was added. An optimal concentration of purified mouse anti-cytochrome $c$ (BD Sciences) and goat anti-mouse antibody conjugating FITC (Thermo Fisher Scientific) were added to the coverslips. At the last $5 \mathrm{~min}$ of incubation, the nuclear staining dye Hoechst (33342; Molecular Probes) was added. All coverslips were mounted to the slides conversely. Scanning and detection were processed under confocal laser scanning microscopy (FV1000; Olympus).

Western blotting. A549 cells were seeded in 100-mm dishes followed by $24 \mathrm{~h}$ of treatment with different concentrations of S2. After harvesting and washing, the cell pellets were re-suspended in whole cell lysis buffer on ice. The cell lysate was collected by centrifugation at $10,000 \mathrm{x}$ g at $4^{\circ} \mathrm{C}$ for $30 \mathrm{~min}$ after incubation overnight at $-20^{\circ} \mathrm{C}$. The protein concentration of each sample supernatant was quantified by using the DC Protein Assay kit (Bio-Rad, Hercules, CA, USA). After normalization, $80 \mu \mathrm{g}$ of proteins were loaded to $4-12 \%$ SDS-PAGE to separate under a voltage of 80-120 V. After transferring to the polyvinylidene fluoride (PVDF) membrane (Millipore Corp., USA), the membrane was blocked with non-fat dry milk $(5 \% \mathrm{w} / \mathrm{v})$ or BSA at room temperature for $1 \mathrm{~h}$. Dilution of the primary antibodies and secondary antibodies were adjusted according to the manufacturer's instructions (Cell Signaling Technologies, Danvers, MA, USA; Santa Cruz Biotechnology). Blots were developed using the ECL Chemiluminescence Detection Reagent (GE Healthcare) according to the manufacturer's instructions. Densitometric analysis was performed with ImageJ software. 


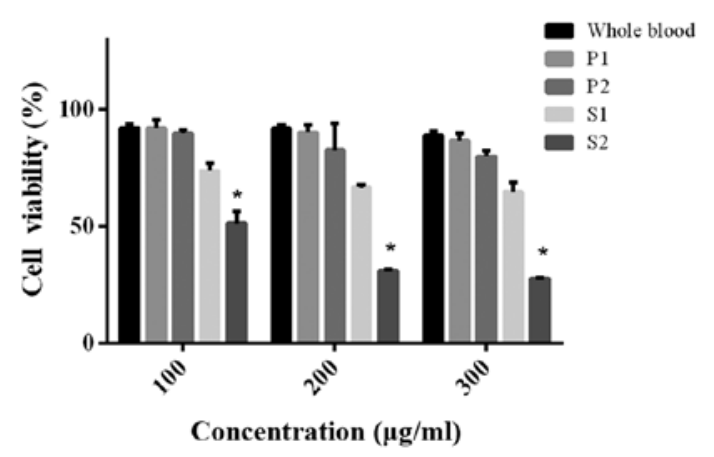

Figure 4. Effect of different concentrations of extracts on cell viability using the MTT assay. P1, peak 1 in residue; $P 2$, peak 2 in residue; $S 1$, peak 1 in supernatant; S2, peak 2 in supernatant. Means $\pm S D, n=3 ;{ }^{*} p<0.05$ vs. whole blood.

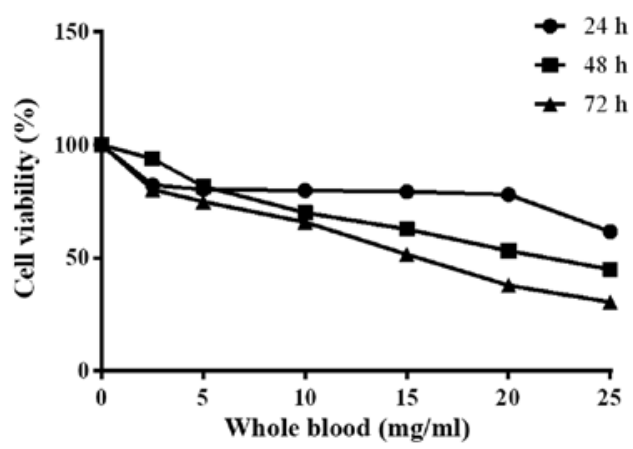

Figure 5. Effect of different concentrations of whole blood on cell viability using the MTT assay. Treatments for 24,48 and $72 \mathrm{~h}$, respectively. Means $\pm \mathrm{SD}, \mathrm{n}=3$.

A

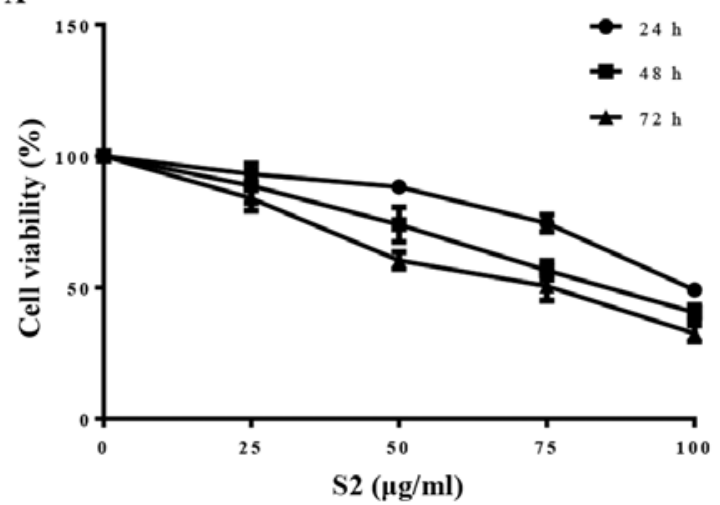

B

\begin{tabular}{lccc}
\hline & $24 \mathrm{~h}$ & $48 \mathrm{~h}$ & $72 \mathrm{~h}$ \\
Whole blood $(\mathbf{m g} / \mathbf{m l})$ & NA & 19.8 & 15.8 \\
S2 $(\mathbf{m g} / \mathbf{m l})$ & 0.101 & 0.085 & 0.068 \\
\hline
\end{tabular}

Figure 6. Effect of different concentrations of S2 on cell viability using the MTT assay. (A) Treatments for 24,48 and $72 \mathrm{~h}$, respectively. (B) The half maximal inhibitory concentration $\left(\mathrm{IC}_{50}\right.$ ) on A549 cells. Means $\pm \mathrm{SD}, \mathrm{n}=3$.

Statistical analysis. Statistical analysis of the raw data was carried out by one-way analysis of variance (ANOVA)

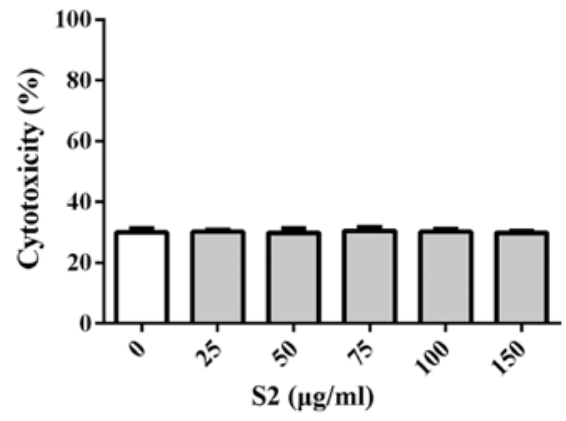

Figure 7. Effect of different concentrations of S2 on cell cytotoxicity using the LDH assay. Means \pm SD, $n=3$.

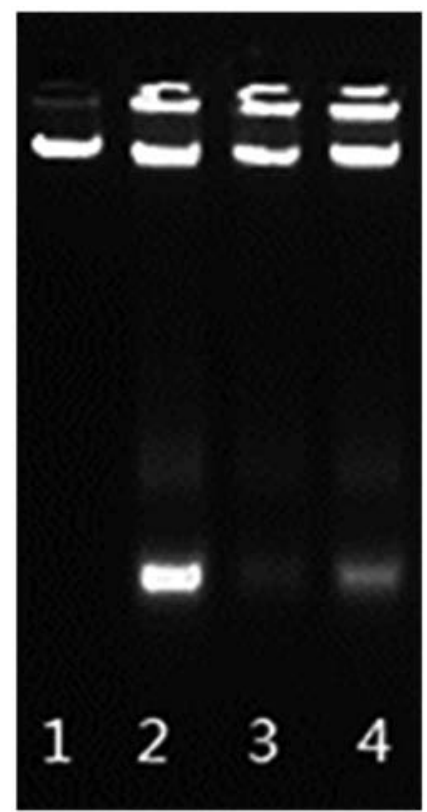

Figure 8. Effect of $200 \mu \mathrm{g} / \mathrm{ml}$ of S2 on DNA fragmentation under UV gel image. Lane 1, control; lane 2, 24 h; lane 3, 48 h; lane 4, 72 h; n=3.

followed by Tukey's post hoc test. The data are expressed as means \pm SD as indicated. Significance was accepted at $\mathrm{p}<0.05$.

\section{Results}

Chromatographic analysis of crocodile blood extracts and $S 2$ fractions. The fractions collected from the precipitation and supernatant were separated according to molecular size (Figs. 1 and 2). The chromatogram profile showed a higher concentration of less polarity in whole blood (Fig. 3A). After precipitation, the less polar parts could not be found but the most polar portion were eluted (Fig. 3B).

Detection of apoptosis and cell cycle distribution. Cell viability showed no significant change after treatment with residues including $\mathrm{P} 1$ and $\mathrm{P} 2$, but decreased after treatment with S1 and S2. S2 displayed more significant efficacy (Fig. 4). The whole blood extract displayed inhibitory effects on cell viability (Fig. 5). Cell growth was prohibited in a dose- and time-dependent manner after treatment with S2 (Fig. 6A) with a low $\mathrm{IC}_{50}$ value (Fig. 6B). Treatment 

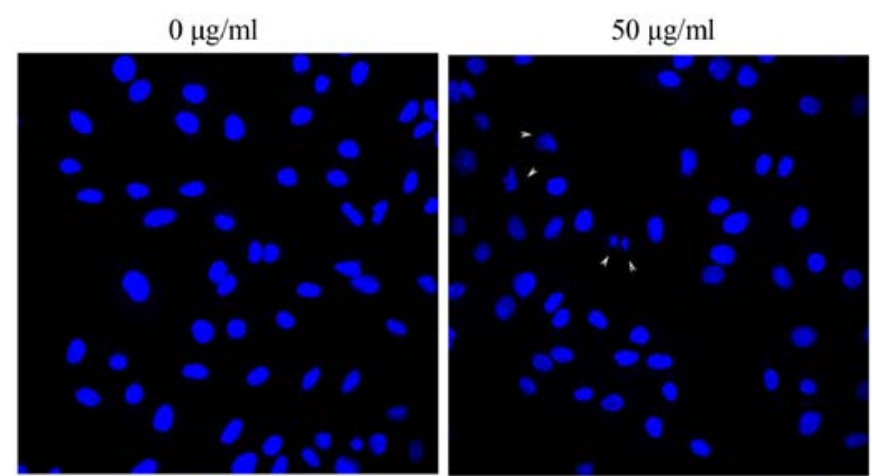

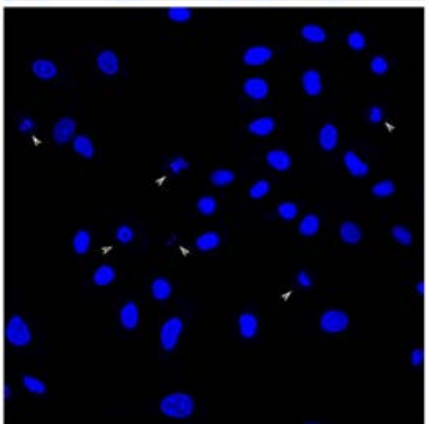

$100 \mu \mathrm{g} / \mathrm{ml}$

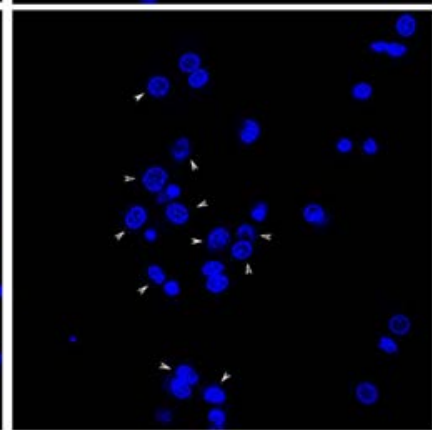

$200 \mu \mathrm{g} / \mathrm{ml}$

Figure 9. Effect of different concentrations of S2 on DNA condensation using Hoechst under confocal laser scanning microscopy. Arrow heads indicate DNA condensations. Magnification, $x 60 ; n=3$.

A

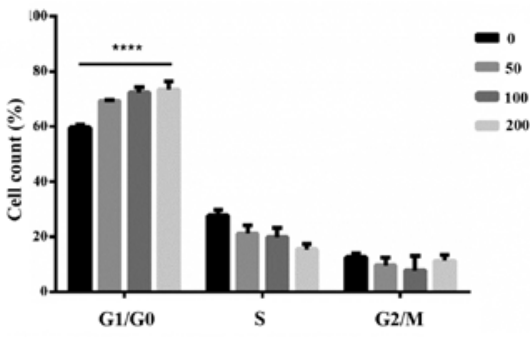

B
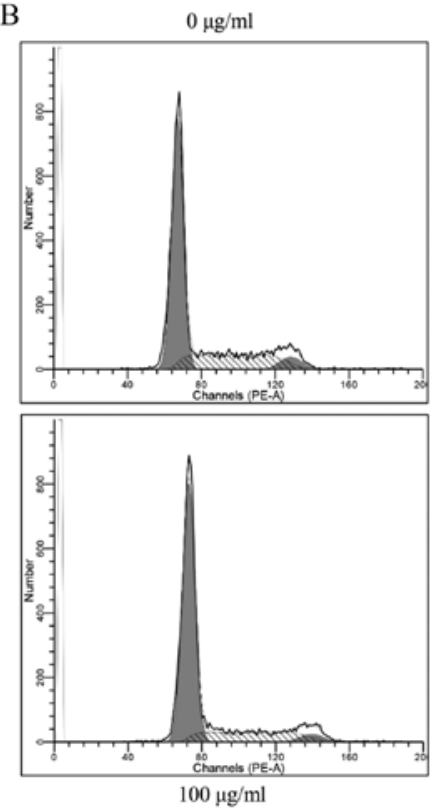

Figure 10. Effect of different concentrations of S2 on the cell cycle using propidium iodide (PI) by flow cytometry. (A) Statistical data analysis of the cell percentage in each phase. (B) Images of the cell cycle. Means $\pm S D, n=3$; ***** $\mathrm{p}<0.0001$
A

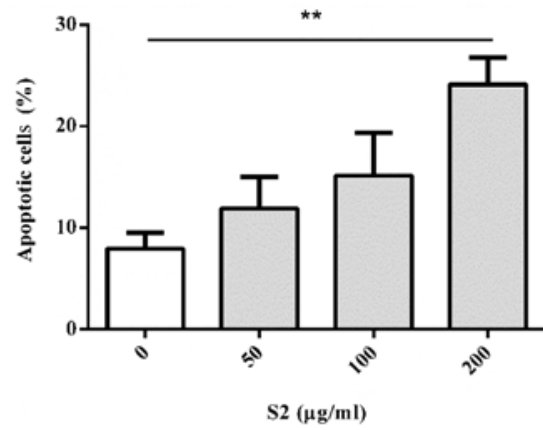

B
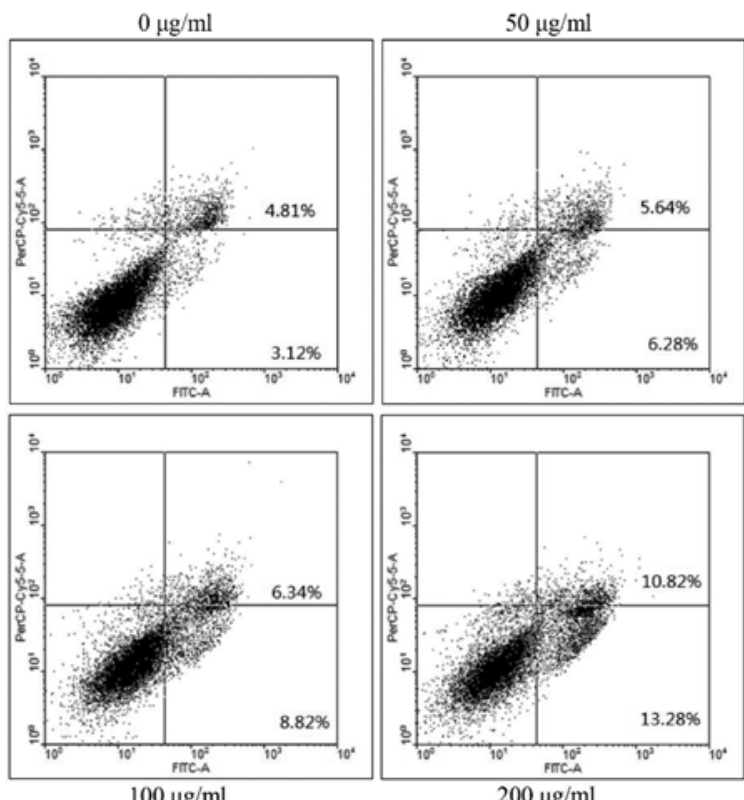

Figure 11. Effect of different concentrations of $\mathrm{S} 2$ on apoptosis by fluorescence-activated sorting analysis using Annexin V-FITC and propidium iodide (PI) by flow cytometry. (A) Statistical analysis of the cell populations. (B) Images of the cell populations. Means $\pm \mathrm{SD}, \mathrm{n}=3 ;{ }^{* *} \mathrm{p}<0.01$.

with S2 revealed no cytotoxicity to cells concurrent with increasing concentrations (Fig. 7). DNA ladder was found in the early $24 \mathrm{~h}$ of treatment while fragments were not detected in the control under the same exposure time (Fig. 8). DNA condensations were observed after treatment with S2 after $24 \mathrm{~h}$ (Fig. 9). There was a significant increase in the percentage of cells in the G0/G1 phase compared to that noted in the control but a decreasing trend in the $\mathrm{S}$ phase, as well as the slight changes in the $\mathrm{G} 2 / \mathrm{M}$ phase were not obvious (Fig. 10). The percentage of FITC-positive and double-positive cells showed an increasing trend with S2 concentrations (Fig. 11). The appearance of ROS in the control group was not detected but the amount and intensities of ROS increased (Fig. 12). After treatment with various concentrations of $\mathrm{S} 2$, the cell numbers decreased with the increase in $\mathrm{S} 2$ concentrations with a signal of higher intensity of FITC and lower intensity of PE (Fig. 13B). Moreover, at the higher concentration of $\mathrm{S} 2$, a more obvious change was observed after $24 \mathrm{~h}$ (Fig. 13A). Aggregations were found in mitochondria followed by treatment with S2 (Fig. 14). The co-localization of green vs. red signal shifted after treatment with S2 (Fig. 15). The fluorescent intensity of caspase-3/7 showed a significant increase (Fig. 16). 


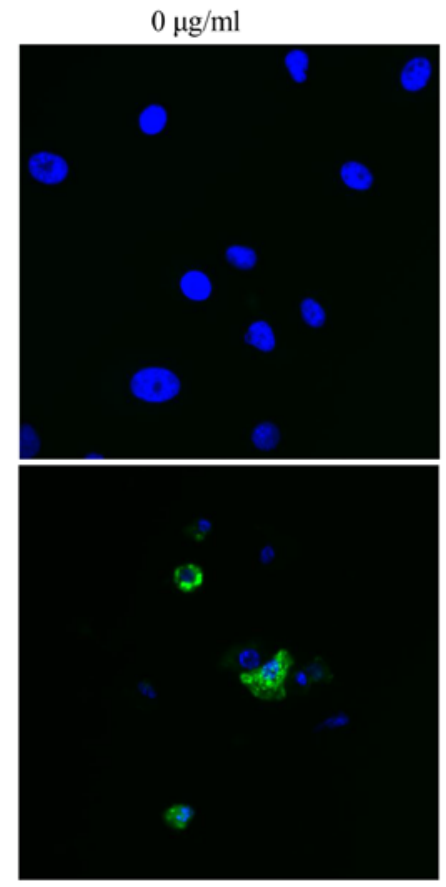

$100 \mu \mathrm{g} / \mathrm{ml}$
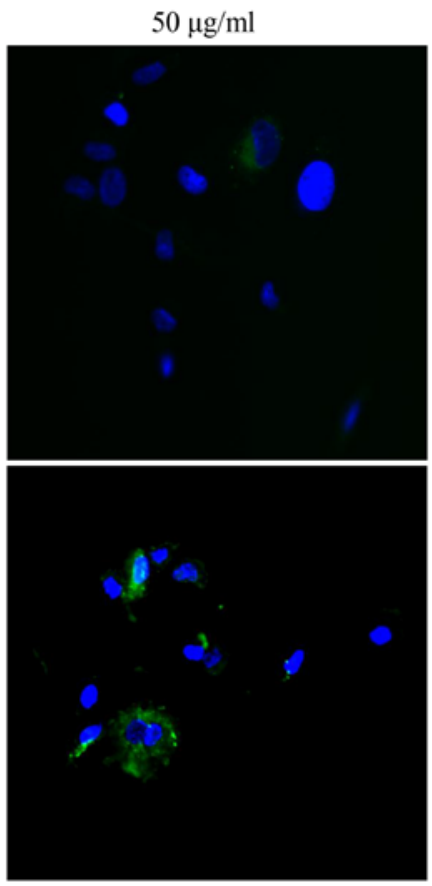

$200 \mu \mathrm{g} / \mathrm{ml}$

Figure 12. Effect of different concentrations of $\mathrm{S} 2$ on induction of reactive oxygen species (ROS) using fluorescent microscopy. Blue, nucleus with Hoechst; Green, ROS with carboxy-H $\mathrm{H}_{2}$ DCFDA. Magnification, x20; n=3.
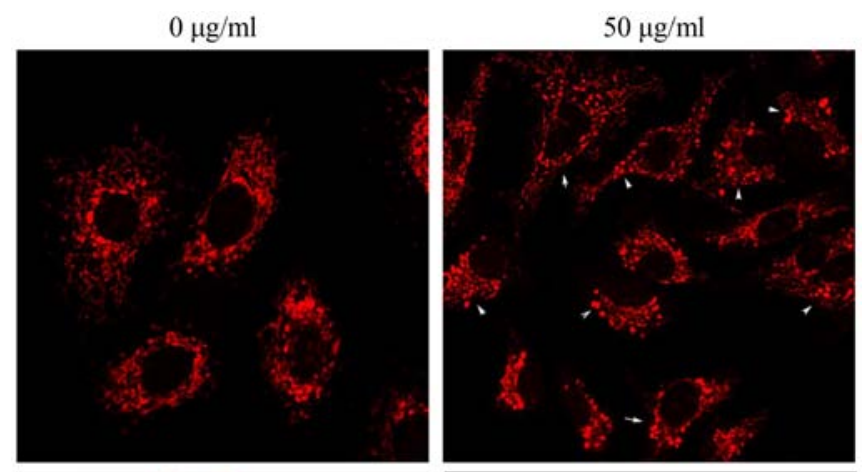

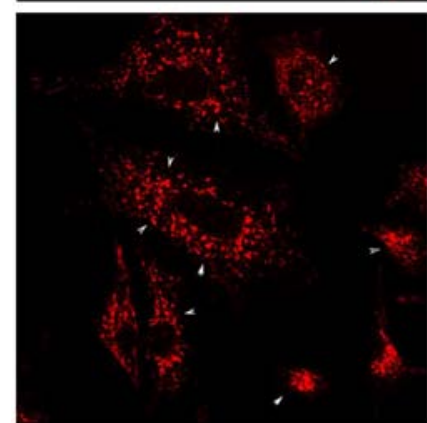

$100 \mu \mathrm{g} / \mathrm{ml}$

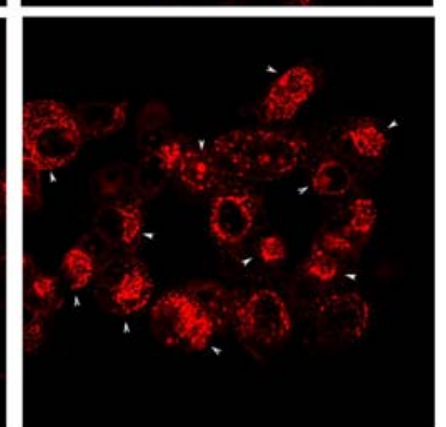

$200 \mu \mathrm{g} / \mathrm{ml}$
Figure 14. Effect of different concentrations of S2 on mitochondrial aggregation using MitoTracker Red under confocal laser scanning microscopy. Arrow heads indicate mitochondrial aggregation. Magnification, $x 60 ; n=3$.

Expression levels of proteins. Following treatment with various concentrations of S2, the expression level of Bcl-2 decreased and the trend became significant when the $\mathrm{S} 2$ concentrations increased whereas expression of Bax showed a total opposite trend. With increasing concentrations, an upregulated expression level of Bax was noted (Fig. 17). Expression levels of another protein in the Bcl-2 family, Bid, displayed an increasing trend with a reverse change in caspase-8 (Fig. 18). The expression of caspase family proteins showed similar changes, with downregulation of wild types and upregulation of the cleaved forms. The expression of PARP decreased together with the decreasing expression of cleaved PARP (Fig. 19). The expression level of cell cycle-related proteins, MDM2 and PCNA, showed a decrease when p21 and p53 were upregulated (Fig. 20). The expression of proteins associated with the PI3K/AKT survival pathway, wild-type Akt, PDK1 and GSK-3 $\beta$ showed no significant changes compared to the control. In contrast, the phosphorylated forms of the above proteins and c-Raf were decreased. Furthermore, wild-type PTEN showed an increasing trend while phosphorylated PTEN exhibited a significant decrease (Fig. 21).

\section{Discussion}

The active fractions of the alligator blood extract were applied to study their effects on colorectal cancer cell lines. The S2 fractions showed the highest effects on cell growth inhibition which indicated that the $\mathrm{S} 2$ fractions contained the active components. The HPLC profile suggested that the active components might remain in the polar parts but could not be further separated. When cells were at the last stage of apoptosis, DNA condensation and cleavage of certain

Figure 13. Effect of different concentrations of S2 on mitochondria membrane permeability using JC-1 by flow cytometry. (A) Statistical data analysis of cell population. (B) Images of the population. Means $\pm S D, n=3$ $\mathrm{p}<0.0001$ 


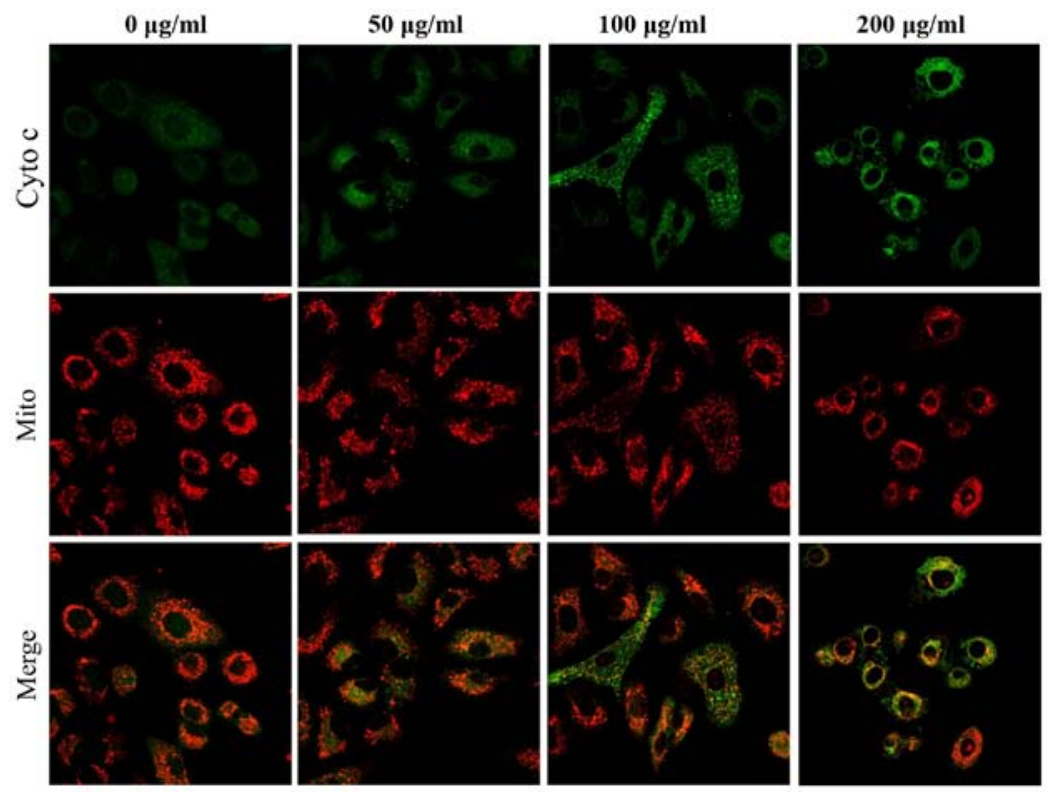

Figure 15. Effect of different concentrations of $\mathrm{S} 2$ on the release of cytochrome $c$ under confocal laser scanning microscopy. Cyto $c$, anti-cytochrome $c$; Mito, mitochondria by MitoTracker Red; Merge, co-localization. Magnification, x60; $n=3$.

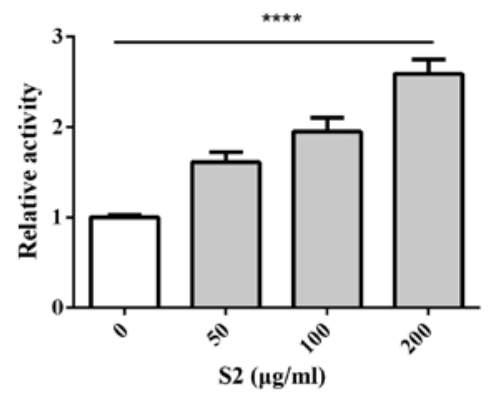

Figure 16. Effect of different concentrations of $\mathrm{S} 2$ on the activities of caspase- 3 and caspase-7. Means $\pm \mathrm{SD}, \mathrm{n}=3 ;{ }^{* * * *} \mathrm{p}<0.0001$.

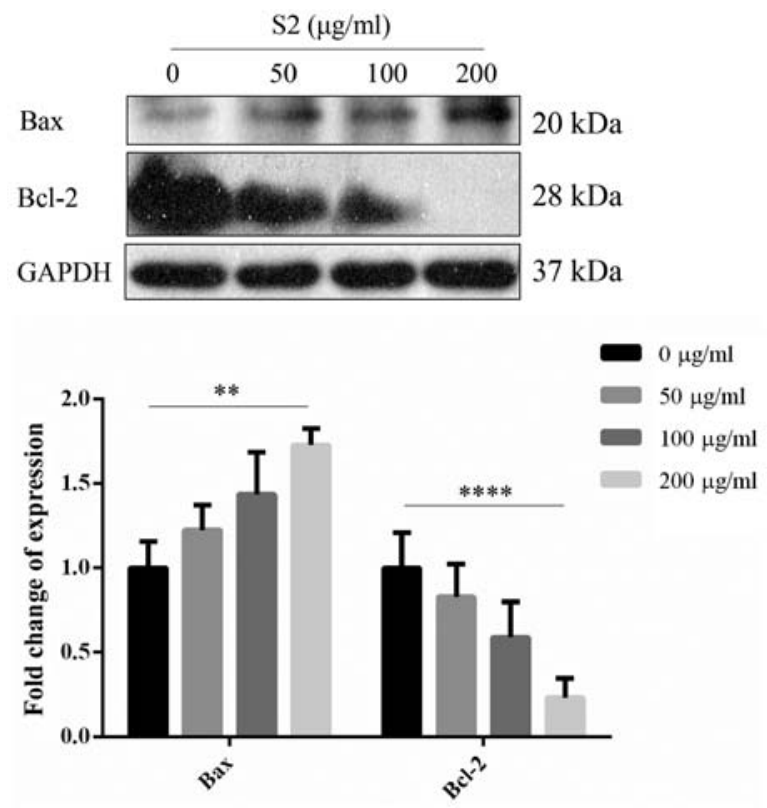

Figure 17. Effect of different concentrations of S2 on the protein expression of Bax and Bcl-2. Images of expression intensity and statistical data analysis of protein relative expression level over the control are shown. GAPDH was used for normalization. Means $\pm \mathrm{SD}, \mathrm{n}=3 ;{ }^{* *} \mathrm{p}<0.01 ;{ }^{* * * *} \mathrm{p}<0.0001$.

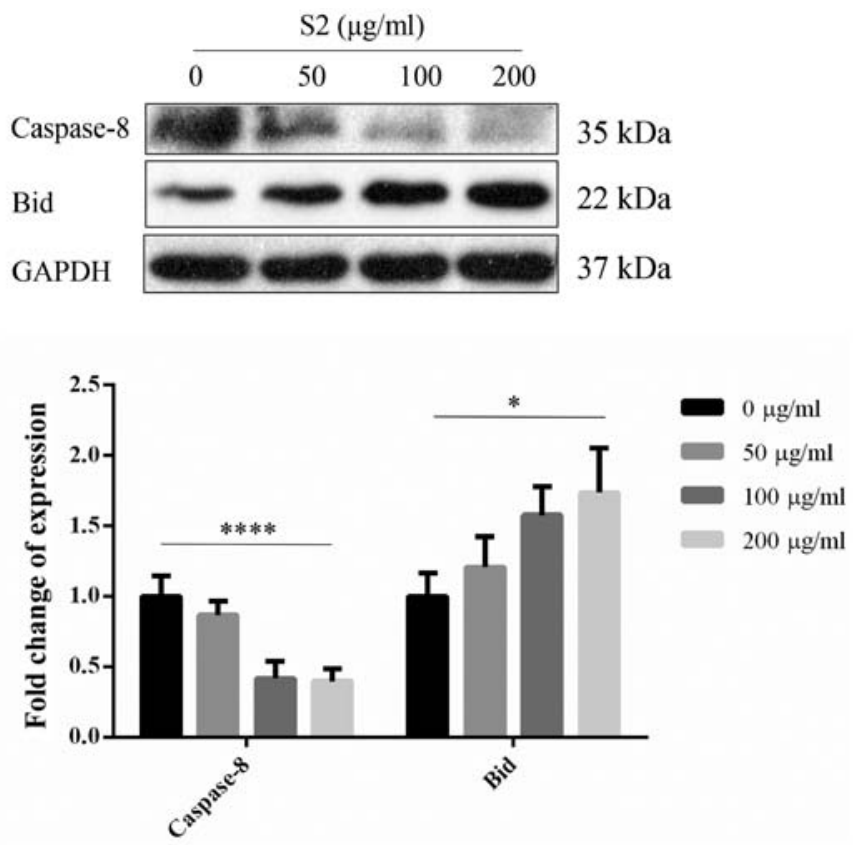

Figure 18. Effect of different concentrations of $\mathrm{S} 2$ on the protein expression of extrinsic apoptosis regulation pathway. Images of expression intensity and statistical data analysis of protein relative expression level over the control are shown. GAPDH was used for normalization. Means $\pm \mathrm{SD}, \mathrm{n}=3$; " $\mathrm{p}<0.05$; ***** $<<0.0001$.

substrates occurred and led to DNA fragmentation (7). S2 induced DNA fragmentation with apoptosis (8). S2 induced cell cycle arrest in the G0/G1 phase. Several proteins associated with cell cycle arrest were detected. MDM2 is a negative regulator of $\mathrm{p} 53$ protein. Through binding to $\mathrm{p} 53$, MDM2 exerts its function in facilitating the degradation of $\mathrm{p} 53$, which subsequently prohibits cell cycle arrest (9). Downregulation of MDM2 enables the implementation of p53 in regulating cell cycle progression and DNA repair (10). A decrease in PCNA 


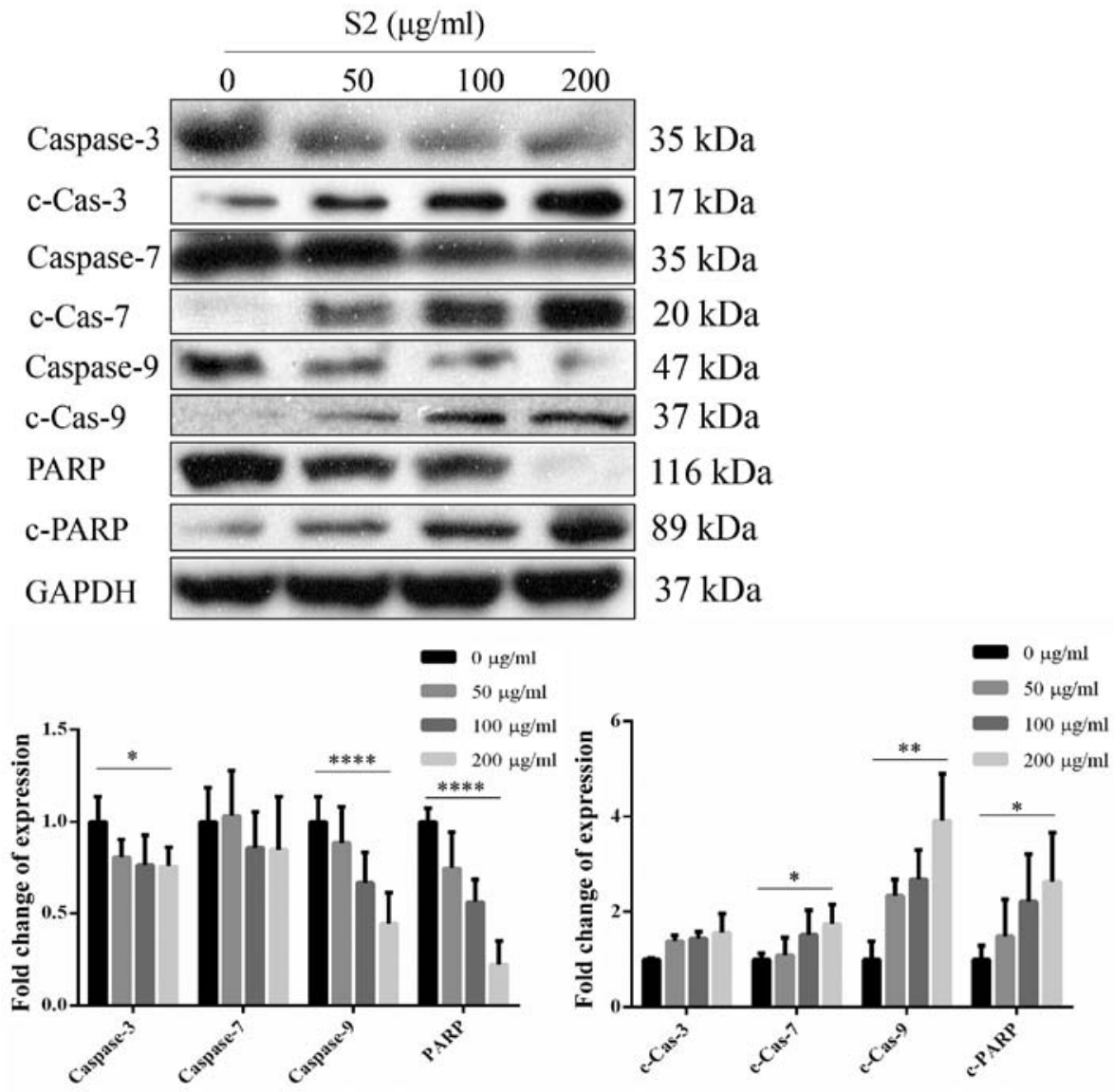

Figure 19. Effect of different concentrations of S2 on the protein expression of the caspase family and PARP. Images of expression intensity and statistical data analysis of protein relative expression level over the control are shown. GAPDH was used for normalization. Means \pm SD, $\mathrm{n}=3 ;{ }^{*} \mathrm{p}<0.05 ;{ }^{* *} \mathrm{p}<0.01 ;{ }^{* * * * *} \mathrm{p}<0.0001$.

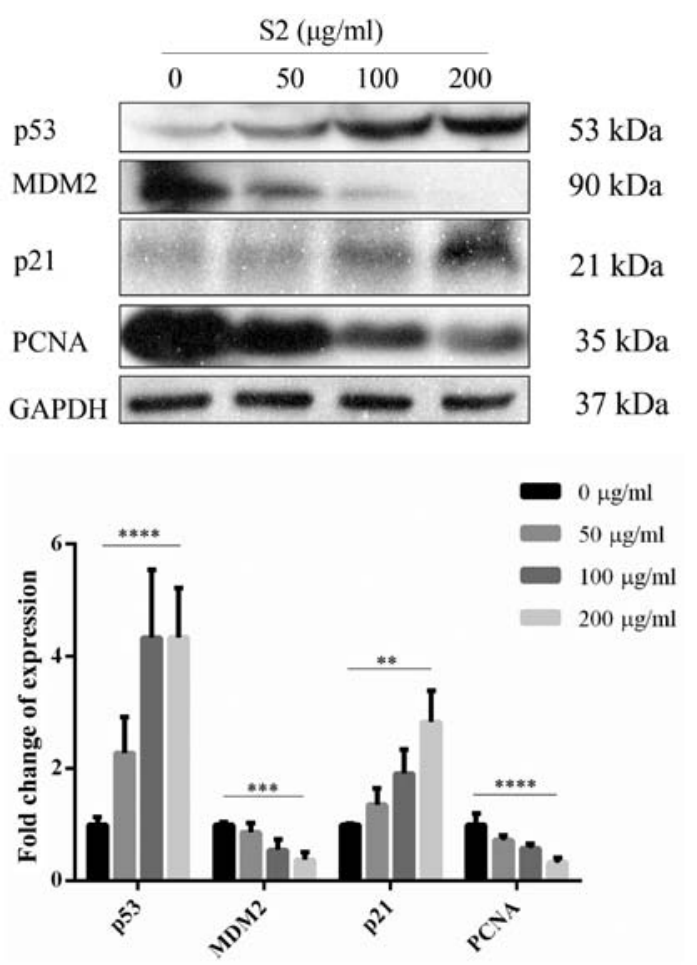

Figure 20. Effect of different concentrations of $\mathrm{S} 2$ on the protein expression of cell cycle regulation pathway. Images of expression intensity and statistical data analysis of protein relative expression level over the control are shown. GAPDH was used for normalization. Means $\pm \mathrm{SD}, \mathrm{n}=3 ;{ }^{* *} \mathrm{p}<0.01 ;{ }^{* * *} \mathrm{p}<0.001$ ****** $\mathrm{p}<0.0001$ promotes the expression of p21 (11). A previous study reported that even when cells were undergoing cell cycle arrest, they stop duplication, but cell death may not occur (12). In the present study, we observed that $\mathrm{S} 2$ induced not only cell cycle arrest, but apoptosis. S2 induced the generation and increase of ROS, which facilitated the rupture of cells (13). The increase in ROS caused disturbance in the mitochondrial membrane potential (14). At higher concentrations of S2, the change in mitochondrial membrane permeability reinforced the changes in the mitochondria. The mitochondrial respiratory activity and the membrane potential were found to be modulated while the collapse in the permeability was observed in early apoptosis (15). It is believed that mitochondrial aggregation is an up-stream event. The release of cytochrome $c$ plays a critical role in mediating the apoptotic intrinsic pathway (16). Cytochrome $c$ was found to be released from the mitochondria which resulted from changes in the mitochondria such as aggregation, an increase in ROS and $\mathrm{Bcl}-2$, along with a decrease in membrane potential and Bax. Cytochrome $c$ that binds to pro-caspase- 9 forms the apoptosome causing a decreasing expression level of pro-caspase- 9 and the increasing level of its activated form (16). Downregulation of caspase- 8 and upregulation of Bid reveal activation of the extrinsic pathway. The activation of caspase- 9 or the activation of caspase- 8 triggers the caspase cascade. Active caspase family proteins cleave certain key substrates and the cells are digested through apoptosis (17). The inactivation of PARP transforms cell death mechanism from necrosis to apoptosis by protecting the integ- 

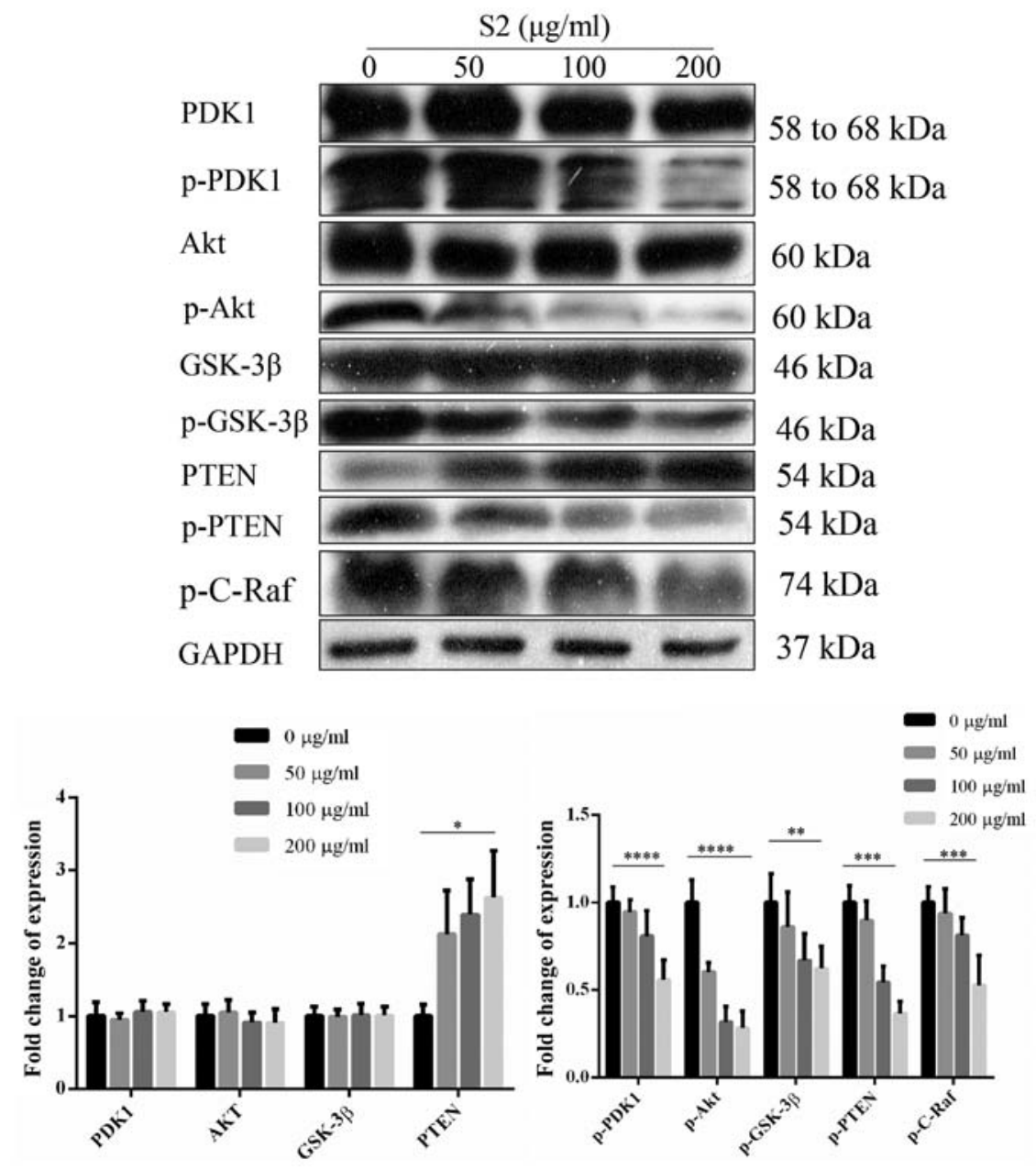

Figure 21. Effect of different concentrations of S2 on the protein expression of the PI3K/Akt pathway. Images of expression intensity and statistical data analysis of protein relative expression level over the control are shown. GAPDH was used for normalization. Means $\pm \mathrm{SD}, \mathrm{n}=3 ;^{*} \mathrm{p}<0.05 ;{ }^{* * *} \mathrm{p}<0.01 ;{ }^{* * * *} \mathrm{p}<0.001 ;$ ***** $\mathrm{p}<0.0001$.

rity of $\mathrm{NAD}^{+}$and ATP formation (18). If the cleavage of PARP is blocked, necrosis presents as the dominating form of cell death resulting from the continued activation of PARP (19). To study the linkage between cell cycle arrest and apoptosis, the PI3K/AKT pathway was examined. PDK1 and AKT showed no obvious changes whereas the phosphorylated forms showed a decreasing trend indicating that inhibition in the initial AKT pathway was via reduction of the active phosphorylated form of the target proteins. The downstream substrate of active AKT, GSK-3 $\beta$, inhibits the activities of p21 and cyclin D1; therefore it enables cells to undergo cell cycle arrest (20). The phosphorylation by AKT resulted in the inhibitory effect on GSK-3 $\beta$ that led to the dysfunction in the regulation. Furthermore, the inhibition of phosphorylated GSK-3 $\beta$ caused the upregulation of $\mathrm{p} 21$ to promote cell cycle arrest. Another substrate of active AKT, MDM2, was downregulated resulting in the upregulation of p53 and subsequently inhibited the activities of Bcl-2 (21). The upregulated expression level of p53 caused cell cycle arrest, but also led to apoptosis (22). The increased expression of active PTEN and the decreased expression of its inactive form, phosphorylated PTEN indicated inhibitory effects on the PI3K/AKT pathway. Change in PTEN activity affects cell cycle progression and apoptosis of cancer cells (23). S2 induced cell cycle arrest and apoptosis through the intrinsic and extrinsic pathways of apoptosis. By modulating the activity of PTEN, S2 inhibited the expression of the PI3K/AKT survival pathway resulting in not only cell cycle arrest but also apoptosis.

\section{Acknowledgements}

This study was supported in part by Mr. Terry Wong of HTL Holdings Ltd.

\section{References}

1. Jemal A, Bray F, Center MM, Ferlay J, Ward E and Forman D: Global cancer statistics. CA Cancer J Clin 61: 69-90, 2011.

2. Hirsch FR, Spreafico A, Novello S, Wood MD, Simms L and Papotti M: The prognostic and predictive role of histology in advanced non-small cell lung cancer: A literature review. J Thorac Oncol 3: 1468-1481, 2008.

3. Crinò L, Weder W, van Meerbeeck $J$ and Felip E; ESMO Guidelines Working Group: Early stage and locally advanced (non-metastatic) non-small-cell lung cancer: ESMO Clinical Practice Guidelines for diagnosis, treatment and follow-up. Ann Oncol 21 (Suppl 5): v103-v115, 2010.

4. Pata S, Yaraksa N, Daduang S, Temsiripong Y, Svasti J, Araki T and Thammasirirak S: Characterization of the novel antibacterial peptide Leucrocin from crocodile (Crocodylus siamensis) white blood cell extracts. Dev Comp Immunol 35: 545-553, 2011. 
5. Phosri S, Mahakunakorn P, Lueangsakulthai J, Jangpromma N, Swatsitang P, Daduang S, Dhiravisit A and Thammasirirak S: An investigation of antioxidant and anti-inflammatory activities from blood components of crocodile (Crocodylus siamensis). Protein J 33: 484-492, 2014.

6. Alley MC, Scudiero DA, Monks A, Hursey ML, Czerwinski MJ, Fine DL, Abbott BJ, Mayo JG, Shoemaker RH and Boyd MR: Feasibility of drug screening with panels of human tumor cell lines using a microculture tetrazolium assay. Cancer Res 48: 589-601, 1988.

7. Kressel M and Groscurth P: Distinction of apoptotic and necrotic cell death by in situ labelling of fragmented DNA. Cell Tissue Res 278: 549-556, 1994.

8. Abraham RT: Cell cycle checkpoint signaling through the ATM and ATR kinases. Genes Dev 15: 2177-2196, 2001.

9. Evan GI and Vousden KH: Proliferation, cell cycle and apoptosis in cancer. Nature 411: 342-348, 2001.

10. Waga S, Hannon GJ, Beach D and Stillman B: The p21 inhibitor of cyclin-dependent kinases controls DNA replication by interaction with PCNA. Nature 369: 574-578, 1994.

11. Bellamy CO, Clarke AR, Wyllie AH and Harrison DJ: p53 Deficiency in liver reduces local control of survival and proliferation, but does not affect apoptosis after DNA damage. FASEB J 11: 591-599, 1997.

12. Green DR: Apoptotic pathways: Ten minutes to dead. Cell 121: 671-674, 2005.

13. Cui $\mathrm{H}$, Kong $\mathrm{Y}$ and Zhang $\mathrm{H}$ : Oxidative stress, mitochondrial dysfunction, and aging. J Signal Transduct 2012: 646354, 2012.

14. Aon MA, Cortassa S and O'Rourke B: Mitochondrial oscillations in physiology and pathophysiology. Adv Exp Med Biol 641: 98-117, 2008

15. Elmore S: Apoptosis: A review of programmed cell death Toxicol Pathol 35: 495-516, 2007.
16. Haga N, Fujita $\mathrm{N}$ and Tsuruo T: Mitochondrial aggregation precedes cytochrome c release from mitochondria during apoptosis. Oncogene 22: 5579-5585, 2003.

17. Denecker G, Vercammen D, Declercq W and Vandenabeele P: Apoptotic and necrotic cell death induced by death domain receptors. Cell Mol Life Sci 58: 356-370, 2001.

18. Fuertes MA, Castilla J, Alonso C and Pérez JM: Cisplatin biochemical mechanism of action: From cytotoxicity to induction of cell death through interconnections between apoptotic and necrotic pathways. Curr Med Chem 10: 257-266, 2003.

19. Yang W, Zhang Y, Li Y, Wu Z and Zhu D: Myostatin induces cyclin D1 degradation to cause cell cycle arrest through a phosphatidylinositol 3-kinase/AKT/GSK-3 $\beta$ pathway and is antagonized by insulin-like growth factor 1 . J Biol Chem 282: 3799-3808, 2007.

20. Vousden KH and Ryan KM: p53 and metabolism. Nat Rev Cancer 9: 691-700, 2009.

21. Finlan LE and Hupp TR: The life cycle of p53: A key target in drug development. In: Apoptosis Pathways as Targets for Novel Therapies in Cancer and Other Diseases. Los M and Gibson SB (eds). Springer, New York, NY, USA, pp157-172, 2005.

22. Yan X, Fraser M, Qiu Q and Tsang BK: Over-expression of PTEN sensitizes human ovarian cancer cells to cisplatin-induced apoptosis in a p53-dependent manner. Gynecol Oncol 102: 348-355, 2006

23. Moghaddam SJ, Li H, Cho SN, Dishop MK, Wistuba II, Ji L, Kurie JM, Dickey BF and Demayo FJ: Promotion of lung carcinogenesis by chronic obstructive pulmonary disease-like airway inflammation in a K-ras-induced mouse model. Am J Respir Cell Mol Biol 40: 443-453, 2009. 